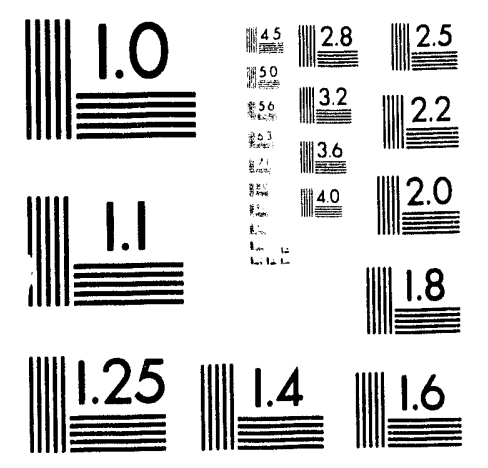



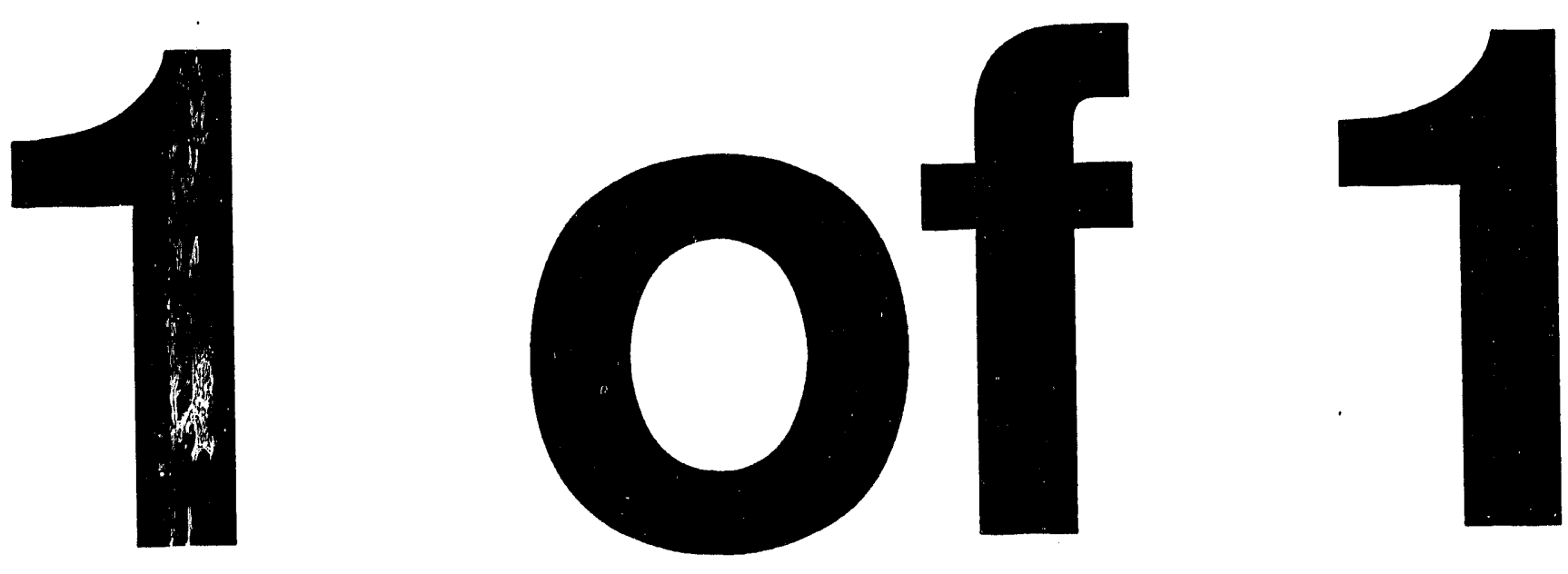


\title{
X-RAY ABSORPTION SPECTROSCOPY OF THE RARE EARTH ORTHOPHOSPHATES
}

\author{
D.K. Shuh \\ L.J. Terminello \\ LA. Boatner \\ M.M. Abraham
}

This paper was prepared for submittal to the 1993 Spring Meeting of the Materials Research Society

San Francisco, CA

April 12-15, 1993

June 1993

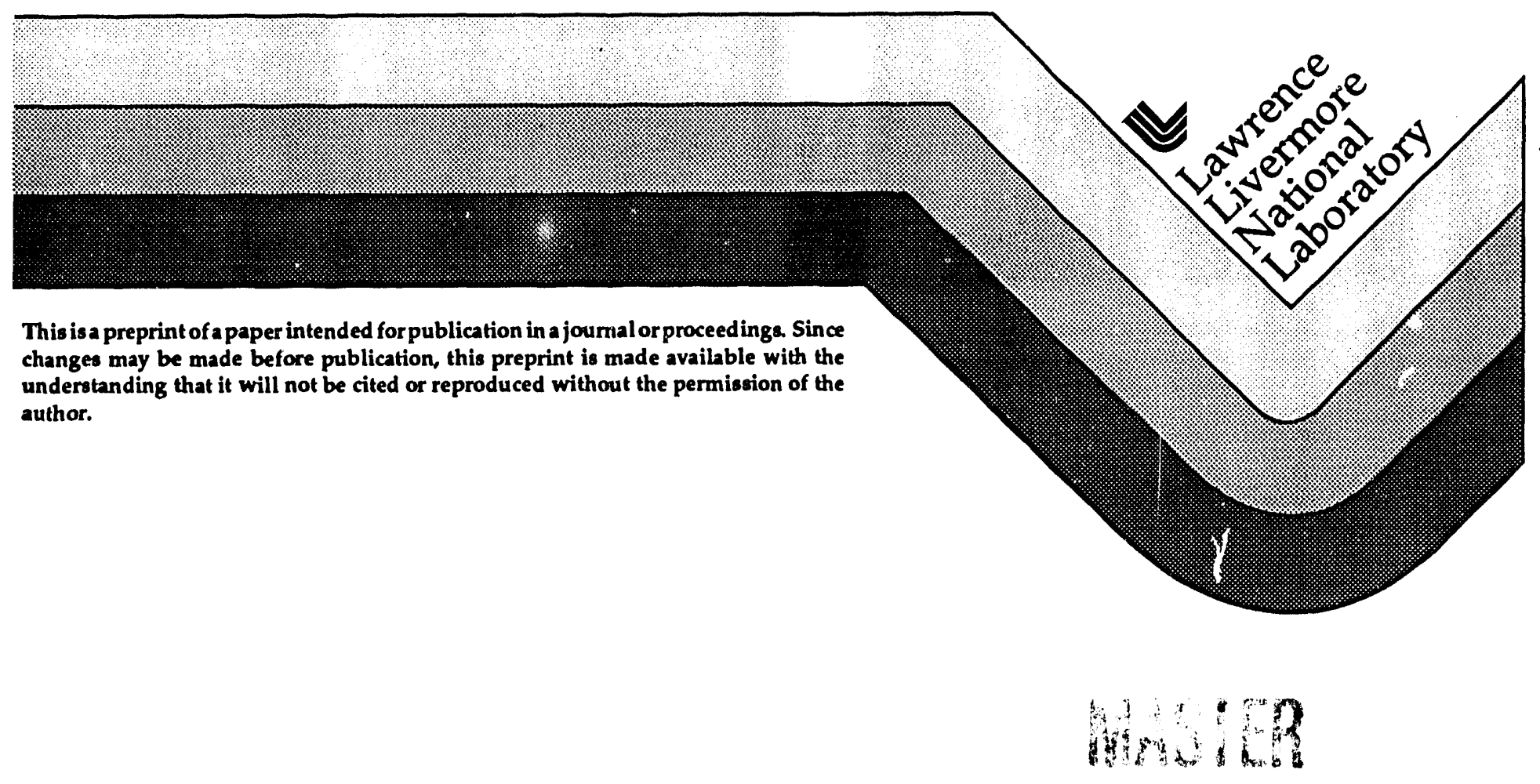




\section{DISCLAIMER}

This document was orepared as an account of work eqoweced by an asency of the United States Goverament. Neither the United States Covernment nor the University of Californin nor any of their employees makes any warranty, express er baplied, or assumes any lezal liability or responsibility for the sccuracy, completeneas, er mefulaess of any infortination, apporatus, produch, or mrocess disclosed, or represeats that its ase would not infringe privately ewmed rigbts. Reference herein to any specific commercial prodwcts. process, or eervice by trade anwe, trademark, manufacturer, or otherwise, does not necessarily constitute or imply it endorsemenh recommendation of favoring by the United Sutes Goverameat or the Univensity of California. The views and opinions of authors expressed berela do cot encessarily state or reflect those of the United States Goverament or the University of Callfornia, and shall not be used for advertising or product eadorsement parposes. 
X-RAY ABSORPTION SPECTROSCOPY

OF THE RARE EARTH ORTHOPHOSPHATES

\author{
D.K. SHUH,* L.J. TERMINELLO,** L.A. BOATNER, ${ }^{* * *}$ AND M.M. ABRAHAM*** \\ *Lawrence Berkeley Laboratory, Berkeley, CA 94720 \\ ** Lawrence Livermore National Laboratory, Livermore, CA 94550 \\ ***Oak Ridge National Laboratory, Oak Ridge, TN 37830

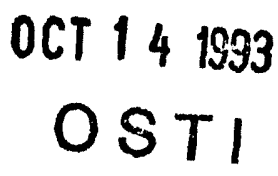

\begin{abstract}
X-ray Absorption Spectroscopy (XAS) of the Rare Earth (RE) 3d levels yields sharp peaks near the edges as a result of strong, quasi-atomic $3 \mathrm{~d}^{10} 4 \mathrm{f}^{\mathrm{n}} \rightarrow 3 \mathrm{~d}^{9} 4 \mathrm{f}^{\mathrm{n}+1}$ transitions and these transitions exhibit a wealth of spectroscopic features. The XAS measurements of single crystal REPO4 (RE = La, Ce, Pr, Nd, Sm, Eu, Gd, Tb, Dy, Er) at the 3d edge were performed in the total yield mode at beam line 8-2 at the Stanford Synchrotron Radiation Laboratory (SSRL). The XAS spectra of the RE ions in the orthophosphate matrix generally resemble the XAS of the corresponding RE metal. This is not unexpected and emphasizes the major contribution of the trivalent state to the electronic transitions at the RE $3 \mathrm{~d}$ edges. These spectra unequivocally identify the transitions originating from well-characterized RE cores and correlate well with previous theoretical investigations.
\end{abstract}

\title{
INTRODUCTION
}

There is a rich history of Rare Earth (RE) 3d X-ray absorption measurements $[1,2]$ that has been augmented recently by improvements in both experimental and theoretical techniques [3,4]. X-ray Absorption Spectroscopy (XAS) of the RE M4,5 edges (3d levels) exhibits sharp peaks near the edges as a result of strong quasi-atomic $3 \mathrm{~d}^{10} 4 \mathrm{f}^{n} \rightarrow 3 \mathrm{~d}^{9} 4 \mathrm{f}^{n+1}$ transitions which contain a wealth of spectroscopic features. These exitonic transitions appear a few electron volts below the true edges as a consequence of the strong core-hole/4f Coulomb interaction that lowers the $4 \mathrm{f}^{\mathrm{n}+1}$ final state by $\sim 10 \mathrm{eV}$ with respect to the Fermi level $\left(E_{F}\right)$. The $M_{4,5}$ spectra consist of two well-separated lines since the spin-orbit $(\Delta S O)$ interaction of the $3 d^{9}$ hole is larger than the $3 d^{9} 4 f^{n+1}$ exchange interaction. Although the purpose of XAS experiments is to obtain information on the RE ground state, the technique also probes the excited electronic final states [5]. The total $3 d^{9} 4 \mathrm{f}^{\mathrm{n}+1}$ multiplets of the RE's are quite complex and even with dipole selection rules limiting the allowed transitions from the ground state, give rise to a large number of possible final states. The technique of total electron yield (TY) X-ray absorption spectroscopy has been shown to be a useful technique for investigation of $4 \mathrm{f}$ occupancy, $4 \mathrm{f}$ hybridization, and valence issues in $\mathrm{RE}$ materials since the TY measurements are known to be proportional to the X-ray absorption coefficient $[3,4]$.

The electronic structures of the RE ions in the orthophosphates $(\mathrm{La}, \mathrm{Ce}, \mathrm{Nd}, ..) \mathrm{PO}_{4}$ are of particular interest since the materials are geological standards, actinide material substitutes/prototypes, and the valence state is clearly defined as tripositive. Thus, the RE orthophosphates are suitable materials for the characterization of transitions originating from trivalent cores and will provide useful information for studies of mixed valence systems. The $\mathrm{RE}$ ions are also ideal from a spectroscopic perspective, since the $\mathrm{M}_{4,5}$ cross sections are large. In addition, several of the lightly-doped RE orthophosphates have recently been shown to be of interest as new scintillator materials [6]. The RE orthophosphates are also the analogs of the corresponding actinide orthophosphates, which have been considered as materials for primary nuclear waste containment and disposal [7]. 


\section{EXPERIMENTAL}

The single crystal RE orthophosphates were prepared by a flux melt technique and have been extensively characterized by $X$-ray diffraction and microprobe [7]. The first seven $\mathrm{REPO}_{4}$ 's have $\mathrm{t}$ he monoclinic monazite structure, where as the second half are the cubic zircon structure. With the exception of $\mathrm{CePO}_{4}$, the rare earth orthophosphates are insulating materials that have band gaps of $\sim 10 \mathrm{eV}$. They are extremely stable and unreactive, requiring no special handling or preparations. The dimensions of the crystals employed in this investigation were approximately $2 \times 3 \mathrm{~mm}$.

The X-ray absorption measurements of the RE orthophosphates at the $\mathrm{M}_{4,5}$ edges were performed in the TY mode on the LLNL/UC PRT beam line 8-2 Spherical Grating Monochromator (SGM) at the Stanford Synchrotron Radiation Laboratory (SSRL). The performance attributes of the beam line and the $55 \mathrm{~m}$ SGM have been described previously $[8,9]$. The spectra were measured with the monochromatic X-ray beam (700-1300 eV) incident at $\sim 45^{\circ}$ to the surface normal, monitoring the photon flux with a Au grid, and by recording the total integrated electron yield from a Channeltron electron multiplier. The $\mathrm{SGM}$ was calibrated from the higher order cut-offs from resident $\mathrm{Fe}, \mathrm{Cu}$, and $\mathrm{Mg}$ filters. The backsides of the samples were attached to a simple manipulator with conductive epoxy, baked to $150^{\circ} \mathrm{C}$, and spectra recorded in an ion-pumped six-way cross that had a base pressure of better than $2 \times 10^{-9}$ Torr.

\section{RESULTS AND DISCUSSION}

Figures 1 and 2 show the XAS spectra of the M4,5 edges of the RE orthophosphates. The $\mathrm{Ce} 3 \mathrm{~d}$ of $\mathrm{CePO}_{4}$ shown in Fig. 1 was collected with second order light and is representative of the total electron yield spectra of the REPO 4 's. The spin-orbit split Ce $3 \mathrm{~d}_{5 / 2}$ and $3 \mathrm{~d}_{3 / 2}$ peaks are the predominant features of the spectrum, whereas the exchange interaction provides the observed fine structure on each. The Ce spectra recorded utilizing first order light (not shown) did not resolve all of the multiplet the fine structure on the spin-orbit peaks. The resolution is estimated at about $-0.5 \mathrm{eV}$ for the spectra taken with second order light, while spectra taken with the first order light are significantly degraded. The La $\mathrm{M}_{4,5}$ lines are the narrowest core-hole states known at such high energies and the $1.5 \mathrm{eV}$ FWHM obtained in this study is similar to those previously measured $[3,4]$. However, the intensity distribution between the spin-orbit pairs in the second order spectra are slightly skewed, since the photon flux monitor primarily accounts for the distribution of first order light. The Sm spectrum of Fig. 1 was collected in first order to avoid interferences with the $\mathrm{O} 1 \mathrm{~s}$ edge of the SmPO4, as well as $O$ 1s perturbations in the photon reference channel. The Gd and Dy spectra of Fig. 2 were recorded in first order since these sample were run independently when the amount of higher order light was significantly reduced. Comparison of these two spectra taken with first order light to previous experimental and theoretical calculations shows that none of the attendant fine structure of either spin-orbit peak is discernable. Thus, high-resolution measurements of RE materials at the $\mathrm{M}_{4,5}$ edges on beam line 8-2 necessitates the use of second order light.

There has been a previous theoretical investigation of the full atomic multiplet in the intermediate coupling regime that included all of the states of the configuration $4 \mathrm{f}^{\mathrm{n}}$ for the ground state, $3 \mathrm{~d}^{9} 4 \mathrm{f}^{\mathrm{n}+1}$ for the excited state, and including all of the ionization states known in the solid state for the rare earth ions [4]. This study utilized calculations from Cowan's program [10] with certain parameters modified and scaled by Thole et. al [4]. The experimentally determined absorption lines of the RE orthophosphates can, in all cases, be adequately described by comparison to these Hartree-Fock calculations of the initial and final states in the intermediate coupling regime. The calculations also suggest that there are some saturation effects in the data that weaken main peak intensity in relation to the smaller multiplet lines. 


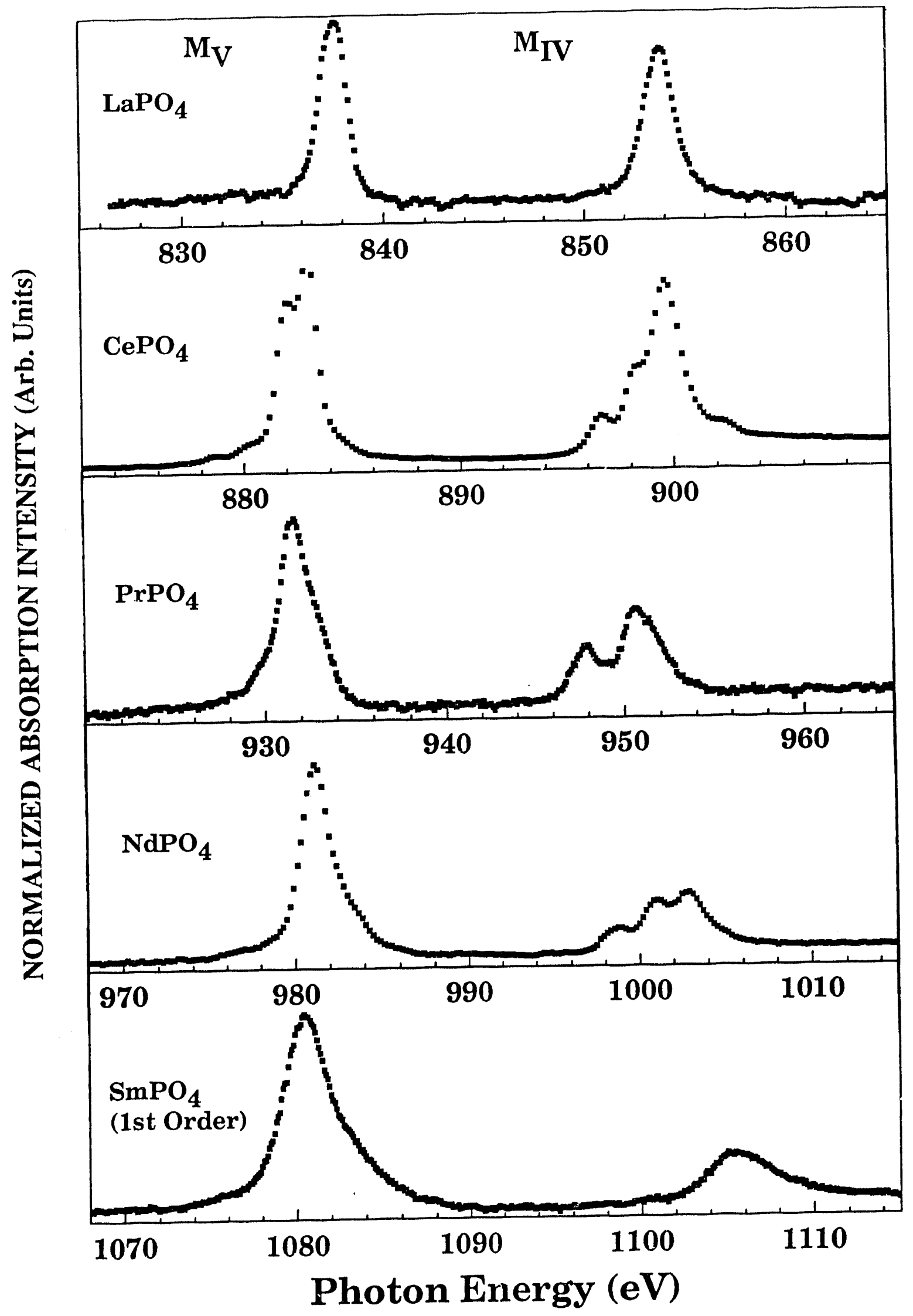

Figure 1. XAS spectra of the rare earth ( $\mathrm{La}, \mathrm{Ce}, \mathrm{Pr}, \mathrm{Nd}, \mathrm{Sm}$ ) orthophosphate $\mathrm{M}_{4,5}$ edges collected with the monochromator diffraction grating satisfying the second order Bragg condition to improve the spectral resolution, except for Sm. The spectra have been normalized to the largest respective feature. 


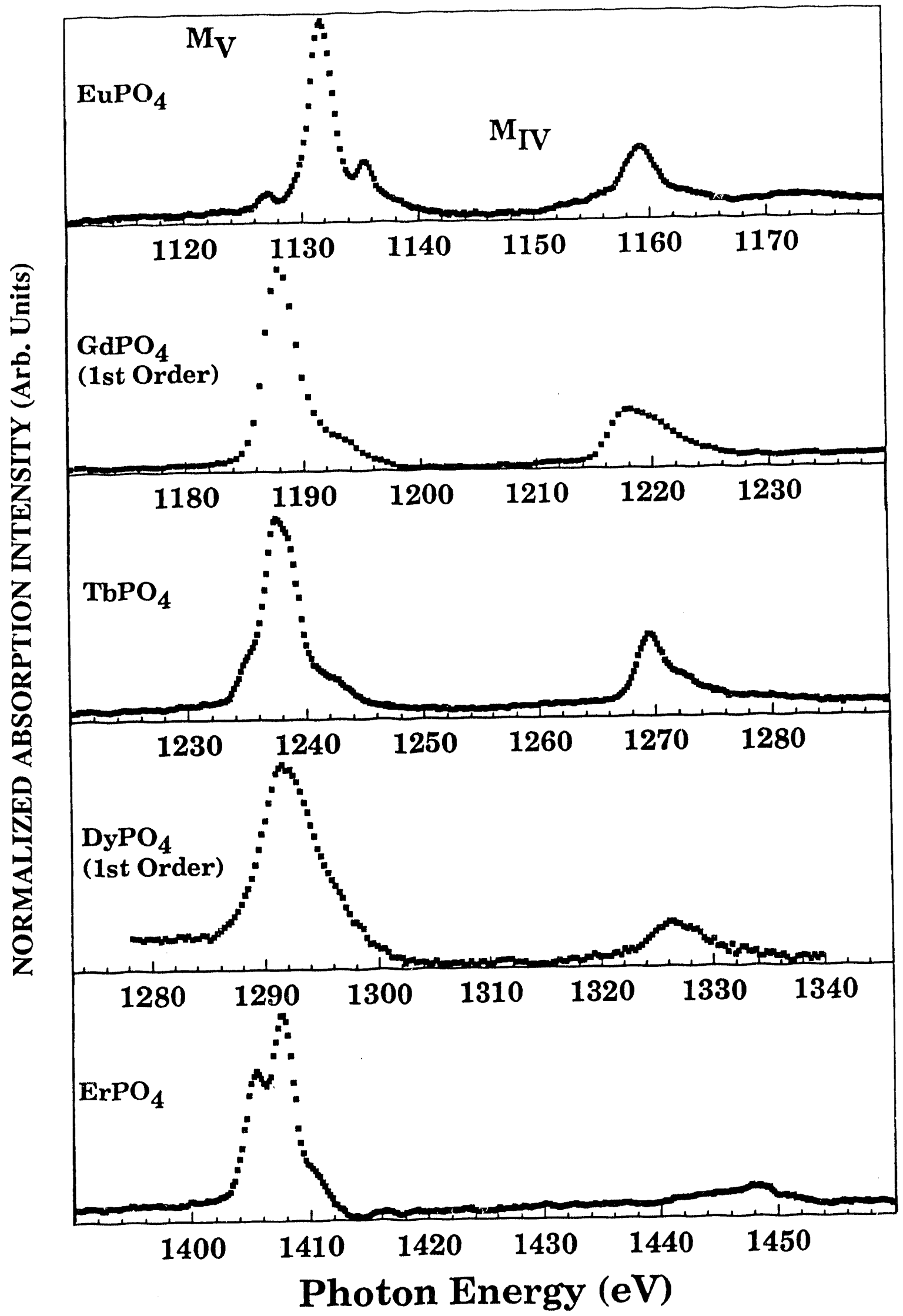

Figure 2. XAS spectra of the rare earth (Eu, Gd, Tb, Dy, Er) orthophosphate M4,5 edges collected with the monochromator diffraction grating satisfying the second order Bragg condition to improve the spectral resolution, unless indicated. These data were also normalized to the largest feature. 
The spectral data of the RE orthophosphates is summarized in Table 1. The peak energies are all systematically about $3 \mathrm{eV}$ greater than expected from previous photoabsorption measurements of the RE metals, whereas the spin-orbit splittings are in complete agreement $[3,4]$.

Table I. Summary of the absorption peak energies of the RE orthophosphates in $\mathrm{eV}$.

\begin{tabular}{|l|r|r|c|}
\hline REPO $_{\mathbf{4}}$ & $\mathbf{3 d}_{\mathbf{5 / 2}}$ & $\mathbf{3 d}_{\mathbf{3 / 2}}$ & Difference $\left(\Delta_{\text {SO }}\right)$ \\
\hline $\mathbf{L a}$ & 837.6 & 853.8 & 16.2 \\
$\mathrm{Ce}$ & 885.5 & 902.7 & 17.2 \\
$\mathbf{P r}$ & 931.6 & 950.7 & 19.1 \\
$\mathbf{N d}$ & 981.2 & 1002.8 & 21.6 \\
$\mathbf{S m}$ & 1080.3 & 1105.1 & 24.8 \\
$\mathbf{E u}$ & 1131.7 & 1159.2 & 27.5 \\
$\mathbf{G d}$ & 1188.1 & 1218.0 & 29.9 \\
$\mathbf{T b}$ & 1237.6 & 1269.5 & 31.9 \\
$\mathbf{D y}$ & 1292.0 & 1326.3 & 34.2 \\
$\mathbf{E r}$ & 1407.6 & 1448.4 & 40.8 \\
\hline
\end{tabular}

\section{CONCLUSIONS}

The XAS spectra of the RE ions in the orthophosphate matrix generally resemble the XAS of the corresponding RE metal. This is not unexpected and emphasizes the major contribution of the trivalent state to the electronic transitions occurring at the RE $3 \mathrm{~d}$ edges. These spectra unequivocally identify the transitions originating from well-characterized $\mathrm{RE}$ cores and correlate well with previous theoretical investigations. The results of these measurements show that XAS of active elements and other hazardous materials safely contained in similar matrices, is feasible and can yield valuable electronic information.

\section{ACKNOWLEDGEMENTS}

We would like to thank K. G. Tirsell for assistance with experimental equipment. This work was supported by the Office of Basic Energy Sciences, Chemical Sciences Division of the U.S. Department of Energy under Contract No. DE-AC03-76SF00098 at LBL and Materials Sciences Division DE-AC05-84OR21400 (ORNL), respectively, and was conducted under the auspices of the Lawrence Livermore National Laboratory under Contract No. W-7405-ENG-48. This work was done at SSRL which is operated by the Department of Energy, Division of Chemical Sciences. 


\section{REFERENCES}

1. J. C. Behmer, A. F. Starace, U. O. Fano, J. Sugar, and J. W. Cooper, Phys. Rev. Lett. 25, 1.521 (1971).

2. J. C. Fuggle, U. O. Hillebrecht, J. -M. Estera, R. C. Karnatak, O. Gunnarsson, K. Schönhammer, Phys. Rev. B 27, 4637 (1983).

3. G. Kaindl, G. Kalkowski, W. D. Brewer, B. Perscheid, and F. Holtzberg, J. Appl. Phys. 55, 1910 (1984).

4. B. T. Thole, G. van der Laan, J. C. Fuggle, G. A. Sawatzky, R. C. Karnatak, and J. -M. Estera, Phys. Rev. B 32, 5107 (1985).

5. J. C. Fuggle in Unoccupied Electronic States, edited by J. C. Fuggle and J. E. Inglesfield, Springer-Verlag, Berlin, (1992).

6. A. Limpicki, E. Bernan, A. J. Wojtowicz, and M. Ralcerzyk, IEEE Trans. Nucl. Sci. (in press).

7. E. Jarosewich and L. A. Boatner, Geostandards Newsletter 15, 397 (1991); L. A. Boatner and R. C. Sales, in Radioactive Waste Forms for the Future, edited by W. Lutze and R. C. Ewing, (Elsevier Science Publishers, 1988) pp. 495-564.

8. K. G. Tirsell and V. P. Karpenko, Nucl. Instr. and Meth. A291, 511 (1990).

9. L. J. Terminello, G. D. Waddill, and J. G. Tobin, Nucl. Instr. and Meth. A319, 271 (1992).

10. R. Cowan, J. Opt. Soc. Am. 58, 808 (1968); R. Cowan in The Theory of Atomic Structure and Spectra, (University of California Press, Berkeley, 1981). 

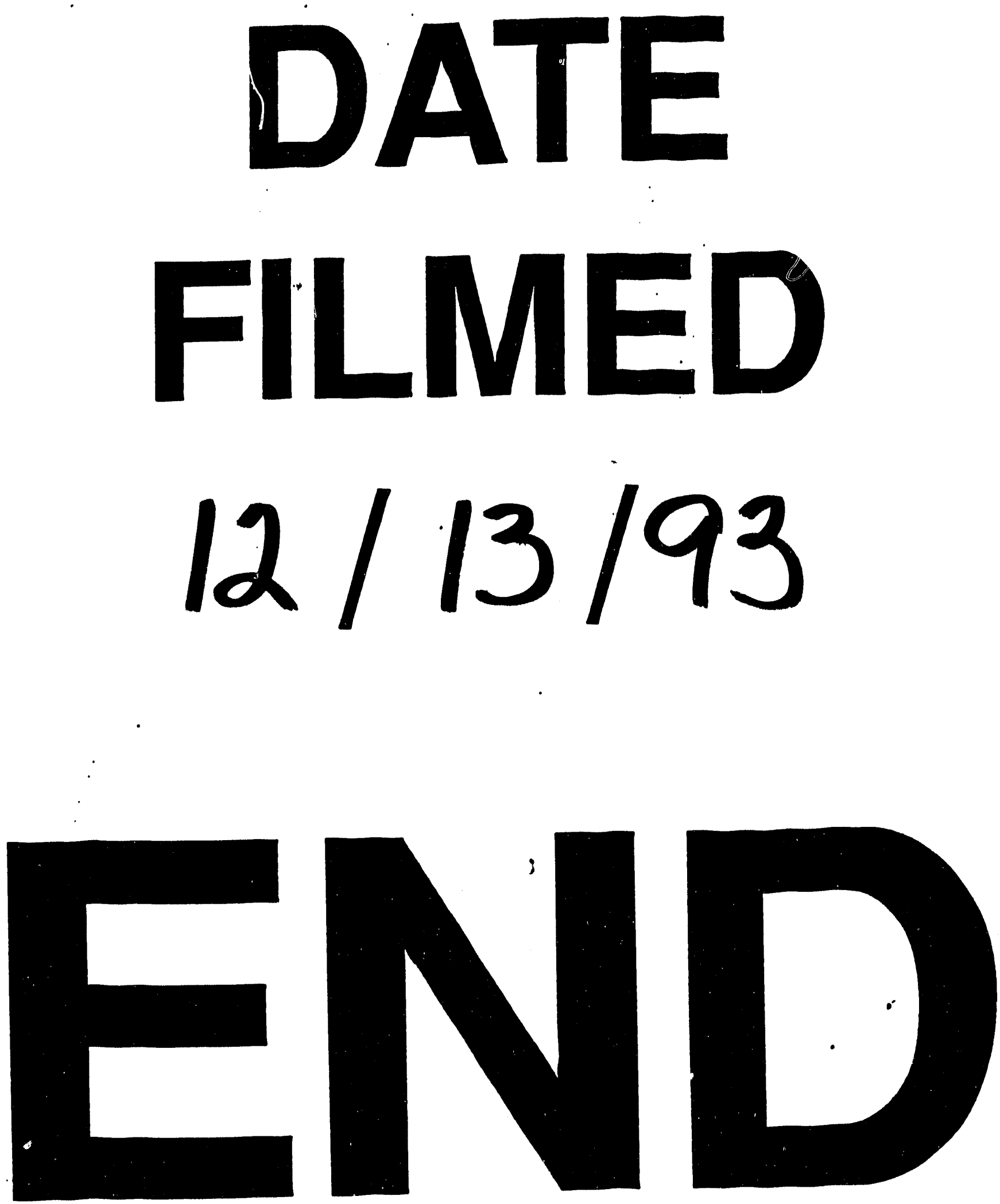
